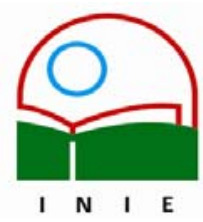

Universidad de Costa Rica

Facultad de Educación

Instituto de Investigación en Educación

ACTUALIDADES INVESTIGATIVAS EN EDUCACION

\title{
LA AGRESIVIDAD HUMANA
}

\section{Olimpia López Avendaño'}

RESUMEN: En este artículo se comparan los planteamientos de Sigmund Freud, Herbert Marcusse y Erich Fromm en torno a la agresividad humana. Analizar esta temática en el contexto actual es relevante dado el incremento de acciones que conllevan gran dosis de violencia tanto en el plano físico, como en el psicológico y espiritual, así como la urgencia de plantear soluciones. La posición de los tres autores permite visualizar la pertinencia de explicaciones que tienden a asumirse en la vida cotidiana en torno a este fenómeno y, sobre todo, construir nuevas perspectivas que las relean, trasciendan y enriquezcan.

Palabras clave: VIOLENCIA/ COMPORTAMIENTO SOCIAL/AGRESIVIDAD HUMANA/

Abstract: In this article the expositions regarding human aggressiveness by Sigmund Freud, Herbert Marcusse and Erich Fromm are compared. The relevance of this subject's analysis in the present context is due to the increase of actions that entail a great dose of violence in the physical, psychological and spiritual planes; and to the urgency of raising solutions. The three authors' position allows us to see how adequate are the explanations that tend to be assumed in everyday life; and above all allow us to build new perspectives that make a new interpretation of them, that extend and enrich them.

Key words: VIOLENCE/ SOCIAL BEHAVIOR/ HUMAN AGGRESSIVENESS/

\section{INTRODUCCIÓN}

La agresividad es uno de los problemas fundamentales que enfrenta la sociedad en el presente. Muchos se preguntan, si el ser humano es hoy más agresivo que en el pasado. La respuesta no es clara, pero sí lo es el que la historia de la humanidad está llena de ejemplos de crueldad y agresividad en sus diversas manifestaciones. El presente, sin embargo, enfrenta a las personas con casos de violencia y agresividad constantemente, dadas las posibilidades que brindan los medios de comunicación. Esta violencia se manifiesta contra el propio yo y los otros en forma alarmante. Por otra parte, estas manifestaciones agresivas adquieren formas propias, según el momento histórico que vivimos.

\footnotetext{
${ }^{1}$ Doctorado en Educación de la Universidad Estatal a Distancia. Doctorado en Filosofía en la Universidad de Costa Rica (egresada). Máster en Sociología de la Universidad de Costa Rica (1990). Licenciada en Administración Educativa de la Universidad de Costa Rica (1984). Bachiller en Educación de la Universidad de Costa Rica (1980). Profesora de Biología y Ciencias Naturales de la Universidad de Costa Rica (1970). Miembro del Consejo Universitario de la Universidad de Costa Rica 20002004.
}

Correo electrónico: olopeza@cariari.ucr.ac.cr

Artículo recibido: 9 de agosto, 2004

Aprobado: 8 de noviembre, 2004 
Freud es uno de los primeros teóricos que analiza la agresividad humana, y sus planteamientos permiten explicar, en gran medida, comportamientos de agresión contra los otros o contra sí mismo en los que incurren individuos a los que se puede considerar normales, pero también neuróticos, o con otras perturbaciones.

A lo largo de su vasta obra, producto de su experiencia psicoanalítica, Freud sugiere y analiza la estructura del aparato psíquico y su dinámica. Las acciones de sus pacientes relacionadas con el masoquismo, su contraparte el sadismo y el narcisismo, lo llevan a vincular la existencia de tendencias agresivas con la energía libidinal y a sugerir la existencia de un instinto de muerte que conduce al ser humano a la destrucción (Más allá del Principio del Placer En: Obras completas, Tomo III, 1981). Además, en El Yo y el Ello, El Malestar en la Cultura (Obras Completas Tomo III, 1981) señala que el ser humano tiene tendencias innatas que lo conducen a agredir a los demás y a su propio yo, pero que son fortalecidas por la cultura.

En el presente documento se analizan las ideas básicas de Freud, en relación con su estructura psíquica del ser humano, así como el origen de las tendencias agresivas y hostiles. En una segunda parte, se presentan algunos argumentos de autores contemporáneos que adversan o asumen las ideas freudianas para explicar el problema de la agresividad.

\section{1- EL SER HUMANO Y LA CULTURA EN FREUD}

Freud define al individuo como Homo lupus, es decir, como un lobo para el hombre. Tal afirmación es justificada en varios de sus ensayos de acuerdo con el análisis del comportamiento de sus pacientes, y con la observación de actitudes hostiles que permean las relaciones de los individuos en sociedad. El racismo, la discriminación de todo tipo, las guerras, son ejemplos de los que se vale para justificar su posición. Así, en El Malestar en la Cultura (Obras Completas, tomo III, 1986, p. 3.046) afirma: "El hombre no es una criatura tierna y necesitada de amor, que solo osará defenderse si se le atacara, sino, por el contrario, un ser entre cuyas disposiciones instintivas también debe incluirse una buena porción de agresividad".

Por otra parte, señala que cuando desaparecen las fuerzas psíquicas antagónicas que inhiben la agresividad, ésta se manifiesta espontáneamente desenmascarando toda la Volumen 4, Número 2, Año 20042 
crueldad de los individuos contra otros. Sin embargo, dado que tal hostilidad no conviene a la sociedad, porque provoca su desintegración, dificulta el trabajo y reduce la productividad humana. Por tal motivo, la cultura propicia mecanismos para contener la fuerza de los instintos, cuyo poder es mayor que el de la razón. Algunos de estos mecanismos para contener la agresividad instintiva son la amistad, las restricciones sexuales, legales y los preceptos morales e ideales. Sin embargo, con esto solamente se logra controlar sus manifestaciones más obvias, pero no así las más sutiles, ejemplo de ello son los comportamientos que se asumen en círculos sociales, donde se descarga hostilidad contra los que no forman parte del mismo, asumiendo la diferencia como una justificación para tales comportamientos. Freud denomina a estos comportamientos, el narcisismo de las pequeñas diferencias.

Por otra parte, visualiza a la cultura como un elemento represor, que limita instintos sexuales y la expresión del principio del placer. Así, la cultura es definida en El Malestar en la Cultura (p. 3.033) como "La suma de las producciones e instituciones que distancian nuestra vida de la de nuestros antecesores animales y que sirven a dos fines: proteger al hombre contra la naturaleza y regular las relaciones de los hombres entre sí.

Asimismo, la posición del individuo como ciudadano, le inducen a asumir esas limitaciones, regulaciones y convenciones y, sobre todo, a aceptar el dominio de las instituciones que el mismo ser humano ha creado. Para lograr lo anterior, se requiere desviar parte de la energía libidinal para orientarla hacia el trabajo, las relaciones filiales y la producción en todo sentido. De este modo, para el autor, el designio de ser felices que impone el principio del placer a los individuos, se vuelve irrealizable en la cultura. Dado lo anterior, la felicidad es la economía libidinal del individuo y, para lograrlo, existen varias posibilidades que van desde la sublimación, el sometimiento al principio de realidad, hasta los mecanismos de fuga o evasión que se pueden encontrar en las drogas y en las neurosis. Sin embargo, el amor plenamente sexual permanece en el inconsciente humano y se resiste a ser sustituido por el cultural, provocando una hostilidad que no se sabe identificar porque es inconsciente.

En síntesis, en la cultura, las relaciones entre los hombres con las instituciones y entre ellos, se encuentran elementos que explican la manifestación de la agresividad humana. 


\section{2- INSTINTOS DE VIDA Y DE MUERTE}

Como se señaló con antelación, Freud en la evolución de su posición teórica, plantea la existencia de los instintos de vida y de muerte. Un aspecto básico en sus investigaciones es el análisis del componente sádico y masoquista en el instinto sexual. El primero que conduce a dañar al objeto del deseo le induce a preguntarse ¿cómo podía emerger del Eros, algo que tiende a dañar al objeto amoroso? Y en relación con el masoquismo señala que:

"la aparición de la tendencia masoquista en la vida instintiva humana plantea, desde el punto de vista económico, un singular enigma. En efecto, si el principio del placer rige los procesos psíquicos de tal manera que el fin inmediato de estos es la evitación de displacer y la consecución del placer, el masoquismo ha de resultar verdaderamente incomprensible. El hecho de que el dolor y el displacer puedan dejar de ser una mera señal de alarma y constituir un fin, supone una paralización del principio del placer: el guardián de nuestra vida anímica habría sido narcotizado (El problema económico del masoquismo, En: Obras Completas, Tomo III, 1981, p. 2.752).

De este modo, admite la existencia de un instinto que une, impulsa la nueva formación y el progreso: Eros. $\mathrm{Y}$, otro que busca volver al estado inicial inanimado, el instinto de muerte. Los instintos de vida o sexuales permiten el encuentro con otras células vivas, son más resistentes contra lo exterior y conservan la vida por más tiempo. Mientras los instintos de vida avanzan, los de muerte retroceden. El instinto de muerte, puede actuar silenciosamente al interior del individuo persiguiendo su destrucción o bien orientarse hacia el mundo exterior, como impulso de agresión y destrucción. Esta última forma de manifestación está al servicio de Eros, porque destruiría algo exterior y no a sí mismo. Sin embargo, cuando la libido trata de domar al instinto de muerte, se mezcla con él formando amalgamas de diversas proporciones. No hay instintos de muerte y de vida puros, sino distintas combinaciones de los mismos.

\section{3- EL SUPERYO O CONSCIENCIA MORAL}

La cultura domina la agresividad del individuo, mediante una instancia moral interior que es su consciencia o superyo. ¿Cómo se forma esta instancia? Cuando la cultura coarta al individuo, se produce un sentimiento agresivo que luego se introyecta, vuelve a su lugar de origen y se incorpora como superyo. El superyo se forma entonces cuando se internaliza la autoridad. La culpa proviene de la ambivalencia afectiva frente al padre: al que se ama y 
odia. Satisfecho el odio, el amor vuelve a surgir en el remordimiento y se erige el superyo. Así, pues, la culpa es el resultado del conflicto de ambivalencia. Es la lucha entre Eros y el instinto de destrucción y de muerte. En la familia se manifiesta en el Edipo. El proceso que comenzó con el padre se generaliza a la humanidad. La cultura es hija de la exaltación de la culpa y eso puede llegar a grados insoportables para el individuo.

En casos de neurosis, la culpa es inconsciente y se expresa en la necesidad permanente de castigo. La culpa puede dirigir el castigo contra uno mismo o al exterior en forma de agresión.

El superyo cultural erige normas e ideales rígidos que a veces son difíciles de lograr por el individuo. Freud concluye este análisis al indicar la neurosis que caracteriza a ciertas sociedades por lo que podría trasladarse el psicoanálisis a la sociedad. Plantea además que "el destino de la especie humana será decidido por la circunstancia de sí y hasta qué punto, el desarrollo cultural logrará hacer frente a las perturbaciones de la vida colectiva emanados del instinto de agresión y de autodestrucción" (El Malestar en la Cultura, En: Obras completas, Tomo III, 1981, p. 3.067).

En síntesis, existe una tendencia natural a la agresividad en los individuos motivada por el instinto de muerte, que conduce al masoquismo a dirigirse contra el yo, o contra los demás. Por otra parte, el superyo, provoca el castigo para mitigar la culpa de origen individual y colectivo que enfrentan los individuos. Ello conduce a destruir, atacar al yo y a los otros. En ello radica la esencia de la agresividad humana.

\section{4- $\quad$ LA POSICIÓN DE FROMM Y MARCUSSE ANTE LA OBRA FREUDIANA}

De acuerdo con Fromm (1989), una de las debilidades de la obra de Freud es la amplitud del concepto de agresividad, pues incluye al sadismo, la destructividad, los deseos de dominio y de poder, y todo ello lo concibe como parte de un instinto; es decir, como innato y natural. Considera que en esos argumentos se mezclan los instintos con las pasiones. En su criterio, los instintos son "soluciones a las necesidades fisiológicas del hombre, y las pasiones condicionadas por el carácter, soluciones a sus necesidades existenciales, son específicamente humanas" (p. 20). 
En su opinión, la debilidad del planeamiento de Freud radica en que aunque sugirió en diversas ocasiones que podía reducirse el principio del instinto de muerte, seguía en pie la idea fundamental: el hombre estaba sometido al influjo de un impulso de destrucción de sí mismo o de los demás y no podía hacer gran cosa para escapar de esa trágica alternativa (1989, p. 31).

Por otra parte, considera que aunque Freud da un gran salto en el análisis de la agresividad, porque ve al organismo desde una perspectiva biológica integral, su teoría "adolece de graves defectos. Se basa en especulaciones bastantes abstractas y raramente ofrece pruebas empíricas convincentes (...) su hipótesis resulta inconsecuente con el comportamiento animal" (1989, p. 31).

De ahí que Fromm proponga que existe una agresividad natural que está al servicio de la supervivencia de la especie, pero también otra de tipo histórico-cultural que se manifiesta en las pasiones y trata de hacer que la vida tenga sentido. Así expresa: "Las pasiones humanas transforman al hombre de mero objeto en protagonista" (1989, p. 23).

Con esta diferenciación, entre principios fisiológicos y sociobiológicos, asume Fromm el análisis de la agresividad. Considera que estos impulsos agresivos caracterizan a la sociedad capitalista y cibernética en la que parece que el lema que se asume es "viva la muerte" y en la que la "conquista de la naturaleza por la máquina forma el verdadero significado del progreso y en que la persona viviente se convierte en apéndice de la máquina” (1989,p. 23). Estas pasiones, aunque no sirven para la supervivencia física en forma directa, son tan fuertes como los instintos.

De acuerdo con Fromm para intentar el cambio de esta actitud necrófila, es necesario modificar la estructura social y política para volver a tener como centro y protagonista de la historia, al ser humano. Así expresa que "La verdadera libertad y la independencia y el fin de todas las formas del poder explotador son las condiciones para la movilización del amor a la vida, única capaz de vencer el amor a la muerte” (1989, p. 25).

Por otra parte, Fromm reconoce como aporte de Freud que "halló la clave para entender las fuerzas que componen el sistema del carácter del hombre y sus contradicciones internas" (1989, p. 95). El descubrimiento de los procesos inconscientes fue revolucionario, porque 
permitía llegar a las raíces del comportamiento humano. La sociedad se liberó de muchos tabúes sexuales y los individuos dejaron de inquietarse, al descubrir en sí mismos, el deseo incestuoso, o bien el narcisismo o el sadismo. A pesar de lo anterior, indica que Freud trató al ello solo como instinto y fue válido en su tiempo, pero era insuficiente para explicar las pasiones humanas lo que había sido su interés primordial. Los avances del psicoanálisis en el presente, se han logrado liberándose del amarre que significa la teoría de la libido y concentrándose más en los procesos inconscientes, las motivaciones que caracterizan las relaciones interpersonales.

Marcusse (1970) coincide con Fromm en que Freud no hace una diferencia adecuada entre lo biológico y lo sociohistórico. Sin embargo, encuentra una salida para utilizar sus descubrimientos sobre la represión en el presente, revisando los aportes de este último. Así, a la represión provocada por la dominación social la llama represión sobrante y a la necesaria para la supervivencia represión básica.

Esta distinción le permite analizar la destructividad actual desde una perspectiva de clase. Así, las actuaciones se explican por la posición en la estratificación social y la actividad competitiva de sus miembros. La sociedad adquisitiva es antagónica y ha racionalizado cada vez más la dominación.

Considera que la sociedad actual, con sus avances tecnológicos, podría disminuir la utilización represiva de la energía humana, pero no lo hace, porque eso atentaría contra el statu quo. Al amor desviado en su fin, como diría Freud, podría ser utilizado cada vez menos, para que la conquista de la naturaleza se apoye más en las máquinas que en los individuos reprimidos, y éstos puedan desalienarse y desarrollarse en un marco de libertad, viviendo bajo el predominio del Eros. Sin embargo, desde el instinto de muerte planteado por Freud, podría pensarse en que "la sola existencia de un instinto así parece engendrar automáticamente, toda red de restricciones y controles instituidos por la civilización; la destructividad innata debe engendrar la represión perpetua” (1970, p. 148). De ahí, el que sea necesario reexaminarla.

Por otra parte, de la obra de Freud se deduce que diversos externos inciden sobre los instintos que rigen la lucha por la existencia y que inciden sobre las manifestaciones del Eros y el principio de muerte. Esta organización de los instintos, según Marcusse "crea la división 
civilizada del trabajo, el progreso y la ley y el orden; pero también inicia la cadena de sucesos que lleva al debilitamiento de Eros, y por tanto, al aumento de la agresividad y al sentimiento de culpa" (1970, p. 149).

En su criterio, este desarrollo no es inherente a la lucha por la existencia, sino que se presenta en la sociedad organizada opresivamente; por lo tanto, en la actualidad esta lucha es irracional y puede ser modificada. Esta posibilidad se asienta en los mismos argumentos de Freud, para quien los instintos son adquiridos históricamente. De esta manera, si cambian las condiciones fundamentales que los determinan, también se modificarán sus efectos. Es cierto que la lucha por la existencia aún se da entre la escasez y la dominación, pero las condiciones actuales de la civilización realmente permiten cambiarlas.

Desde esta perspectiva, la correlación de Freud, represión instintiva- trabajo socialmente útilcivilización, puede ser modificada en liberación instintiva- trabajo socialmente útil- civilización (1970, p. 166). Así, la liberación de Eros podría conducir a crear nuevas y durables relaciones de trabajo no enajenado. Este cambio "alteraría la estructura psíquica, la relación entre Eros y Tánatos, reactivaría los campos de gratificación convertidos en tabúes, y pacificaría las tendencias conservadoras de los instintos" (1970, p.169).

Estos cambios permitirían la liberación de la sexualidad para ponerla al servicio de la sensualidad total humana, no solo de la reproducción. Esto implicaría la posibilidad de una sublimación no represiva de la energía sexual, sublimación sin desexualización, sin desvío del instinto ,sino gratificado por una sexualidad más amplia, pero que sigue siendo erótica.

Por otra parte el autor señala que en el presente, son instituciones impersonales las que ejercen influencia sobre la formación del superyo, más que la familia, la que está debilitada. Asevera que en sus relaciones antagónicas con los padres, de amor y agresión, "la joven generación entraba a la vida social con impulsos ideas y necesidades que eran en gran parte propias" (1970, p. 109).

El ajuste que ello implicaba dejaba cicatrices que impedían el anticonformismo. Hoy, la organización represiva de los instintos parece ser colectiva y el ego parece estar prematuramente socializado por todo un sistema de agentes y agencias extrafamiliares. E padre objeto de agresión edipiana ha sido sustituido por las instituciones. 
De este modo, la agresión debe ser introyectada otra vez, porque cae en el vacío; el odio se encuentra con el sistema organizado, con los colegas sonrientes en la estructura productiva. Ya no hay espacio para encontrarse con su sentido de culpa y vivir con una conciencia propia. Sin embargo, la culpa está ahí y es colectiva, malgastándose las posibilidades humanas en el marco de la deshumanización de la cultura de masas. De ahí la agresión acumulada que no puede ser contenida. Por otra parte, el individuo anestesiado por toda la máquina educativa del sistema se adormece, no vive la angustia. Ahora hay menos posibilidades de fortalecer el principio de realidad mediante identificaciones y sublimaciones creadoras.

Sin embargo, el hecho de que la teoría de la enajenación muestre que el individuo es en la actualidad un mero instrumento de trabajo que no se realiza a sí mismo no debe conducir a pensar en la necesidad de una reactivación de la represión, sino más bien en su eliminación como paso previo a la reconstrucción de nuevas relaciones entre los instintos originales. Eros, libre de la represión sobrante, absorbería el instinto de muerte, contrarrestando la atracción inconsciente de vuelta al estado original, y sustituyéndola por el gusto del estado de vida alcanzado. Esta satisfacción permitiría que la muerte dejara de ser una meta instintiva. La muerte final se aceptaría, después de que se tuviera la posibilidad de vivir una vida plena.

Marcusse (1970) critica a Fromm y a otros psicoanalistas a los que llama revisionistas, porque no plantean la revisión de la estructura social en la que procuran resolver los problemas de personalidad de los individuos. En su criterio se trata de trabajar por la gestación de nuevas formas de individualidad en el marco de relaciones sociales diferentes. De acuerdo con Freud, el amor en nuestra cultura, para que sea constructivo, no puede ser practicado más que en el marco de una sociedad restrictiva. Pero para los revisionistas, emerge armoniosamente en el marco de las estructuras actuales. Para Marcusse allí se plantea una contradicción, porque transforma los problemas sociales en espirituales y les da una solución moral. Las luchas se dan en el espíritu del ser humano. Por ello considera que son más inconsecuentes que Freud; porque si la neurosis es un problema moral, el individuo es responsable de su fracaso. Para Freud un mundo entero separa a la libertad y la felicidad auténticas de los falsos sinónimos que predica la sociedad represiva. Los revisionistas espiritualizaron la libertad y la felicidad. Con el Edipo, Eros libra su primera batalla contra el padre, la dominación, la resignación. Freud no creía en que los cambios 
sociales pudieran cambiar la naturaleza humana y no carecía de fundamentos, pues su teoría se movía del terreno individual e inconsciente, al colectivo e histórico. De ahí que a partir de los principios de Freud, se pueda pensar en cambiar las relaciones entre la cultura y las necesidades instintivas y, por tanto, pensar en un mundo con una organización más adecuada para la humanidad.

\section{CONCLUSIONES}

La obra de Freud sigue siendo fértil para el estudio y búsqueda de soluciones ante la destructividad humana y social en el presente. El análisis realizado por autores como Marcusse, revela su fecundidad para intentar plantear una utopía en la que se visualice una sociedad organizada, de tal forma, que reduzca las tendencias agresivas y fortalezca las posibilidades de vida.

El principio de realidad y las represiones culturales planteadas con gran precisión por Freud, como elementos básicos de la manifestación del instinto de muerte, permiten repensar las relaciones interpersonales en el presente, desde una perspectiva realista, aceptando al ser humano con sus tendencias ambivalentes de capacidad de amar y de odiar, de crear y de destruir. Pero sobre todo ofreciendo un contexto cultural que le posibilite trascenderlos y derivar de ello una vida productiva en el sentido integral del término.

Una de las críticas fundamentales a su obra, radica en haber subsumido todas las manifestaciones agresivas humanas en un instinto. Los instintos por definición son inherentes a la naturaleza biológica humana y se reproducen por la herencia. De ahí que diversos autores ven en las ideas de Freud, una predestinación que impediría pensar en una sociedad no represiva y en individuos pacíficos y con mayor capacidad de amar.

En estos argumentos se visualiza el temor de la humanidad de aceptar su naturaleza biológica innata y sus mecanismos. Ello deriva de una concepción de lo biológico-evolutivo desligada de su dinámica con el medio sociocultural. Por otra parte implica un desconocimiento de las imbricadas relaciones que se dan entre el potencial genético y las relaciones culturales, de tal forma que tal interrelación puede conducir a la manifestación u ocultación de la potencialidad genética. 
De acuerdo con los planteamientos de algunos sociobiólogos y antropólogos, el peso de la cultura sobre la dotación genética y, por tanto, sobre la naturaleza innata humana es tal, que puede modificar el comportamiento humano con más rapidez que la aparición de los cambios evolutivos naturales, que implican miles o millones de años.

En efecto la obra de Freud no realiza una clara separación entre los instintos agresivos que posibilitan el mantenimiento de la especie, su defensa y conservación, de las pasiones humanas como el odio, los celos y otros más. El instinto de muerte los cubre a todos y esta es una debilidad. Sin embargo, ello no impide la utilidad del concepto para explicar las manifestaciones humanas de tipo destructivo en el nivel social e individual. Por otra parte, el psicoanálisis como metodología de superación humana, ha demostrado ser útil en la solución de neurosis, producto de una culpa fuertemente interiorizada que conducía a los sujetos a tratar de destruirse, intentando la muerte.

Igualmente fecunda resulta la posición del autor en relación con la cultura y la adquisición de un superyo individual y colectivo, porque permite encontrar explicación a comportamientos guiados por motivaciones inconscientes, producto de la represión familiar, de grupos cercanos, situaciones escolares u otras, como causas de la socialización, mediante las que el individuo construye socialmente su realidad. La teoría sociológica actual permite definir al conocimiento, el sistema de valores, las creencias y motivaciones humanas, como una construcción social. Estos elementos permiten visualizar la construcción de una sociedad mejor en la que el entorno favorezca un desarrollo psíquico sano.

Tanto la sociobiología como la sociología permiten reconocer los aportes de los principios freudianos, en cuanto a la relación individuo, cultura, represión. Desde luego que no concebidos desde una perspectiva lineal y mecánica en que la base biológica determina al individuo de tal modo que es una marioneta en manos del destino social, para los seres humanos. En este sentido, los aportes de Marcusse al visualizar a la persona, sus instintos y su desarrollo en el marco de una sociedad liberadora son esperanzadores para trascender la agresividad. Individuo y cultura son un binomio inseparable y, si la cultura es construcción humana, el cambio es posible.

Esto se reafirma, si se acepta con Freud que las pulsiones de carácter biológico-social, pueden ser sometidas a las instancias superiores de la razón, antes de actuar, y ello es lo 
que en última instancia determina el comportamiento humano. En este principio se encontraría una dimensión no determinista del planteamiento freudiano. El ser humano puede ejercer una acción voluntaria ante sus impulsos innatos, lo que no podrían hacer los animales. Sin embargo, lo que deseemos o no está influido; es producto de una construcción histórico-social. En el presente, el proceso de socialización está influido por elementos culturalmente poderosos, como los medios de comunicación, que pueden inducir al ser humano a una subutilización de sus posibilidades de distanciamiento y análisis crítico de la realidad. Además de convertir a la violencia en objeto de diversión al alcance de la mano en cualquier momento y edad.

El instinto de muerte parece manifestarse hoy con mucha fuerza, las amenazas a la vida son patentes tanto en el nivel individual como colectivo y ecológico. Hoy, las posibilidades de vida en el planeta están amenazadas. Desde el punto de vista biológico, el Homo sapiens tiene pocas posibilidades de supervivencia, si no se modifica el sistema de relaciones con un medio artificiosamente manipulado, que se volvió contra la vida. Desde el punto de vista psíquico, el sometimiento de las necesidades al principio de realidad, resulta complejo en una sociedad de consumo que manipula el deseo, lo que conduce a frustración, y por tanto, también a la fragmentación del yo. De ahí que Marcusse acierte cuando parte de la necesidad de influir sobre esa realidad para pensar en la recuperación de las posibilidades de vida para el hombre en condiciones más sanas.

La agresividad humana es una realidad concreta. Se vive en carne propia y se visualiza en los otros. Las condiciones sociales enajenantes la desencadenan. No es posible eliminar la agresividad necesaria para la supervivencia de la especie, pero cada día parecen necesitarse mayores dosis para procurar la integridad física y psíquica. De ahí que se requieren canalizar los productos culturales, en beneficio de una reducción de la represión sobrante; pero a partir de una transformación de la realidad material y de las relaciones entre los individuos. Finalmente, el cambio en el contexto, podría propiciar el cambio evolutivo requerido en el nivel de las estructuras biológicas y del comportamiento humano. 


\section{REFERENCIAS}

Freud, Sigmund. (1981). Obras completas. Madrid, España: Editorial Biblioteca Nueva.

Fromm, Erich. (1989). Anatomía de la destructividad humana. México: Editorial Siglo $\mathrm{XXI}$.

Marcusse, Herbert. (1970). Eros y civilización. México: Editorial Joaquín Motiz.

Menninger, Karl. (1952). El hombre contra sí mismo. Argentina, Buenos Aires: Editorial Losada.

Van Riller, Jacques. (1978). La agresividad humana. Barcelona: Editorial Herder. 